Check for updates

Cite this: RSC Adv., 2019, 9, 2608

Received 26th November 2018 Accepted 21st December 2018

DOI: $10.1039 / c 8 r a 09731 c$

rsc.li/rsc-advances

\section{Examining the temporal behavior of the hydrocarbonaceous overlayer on an iron based Fischer-Tropsch catalyst $\uparrow$}

\author{
Robbie Warringham, ${ }^{a}$ Alisha L. Davidson, ${ }^{a}$ Paul B. Webb, (D) *b Robert P. Tooze, ${ }^{c}$ \\ Russel A. Ewings, ${ }^{d}$ Stewart F. Parker (D) d and David Lennon (D) *a
}

\begin{abstract}
In order to examine fundamental processes connected with the use of an unpromoted iron based FischerTropsch synthesis (FTS) catalyst, model studies examining the temporal formation of hydrocarbonaceous species that form over the catalyst are undertaken using a combination of temperature-programmed oxidation, powder X-ray diffraction, Raman scattering, transmission electron microscopy and inelastic neutron scattering (INS). Catalyst samples were exposed to ambient pressure CO hydrogenation at $623 \mathrm{~K}$ for defined periods of time-on-stream $(3,6,12$ and 24 h) prior to analysis. INS reveals a progressive retention of hydrogenous species that is associated with the evolution of a hydrocarbonaceous overlayer, as evidenced by the presence of $\mathrm{sp}^{2}$ and $\mathrm{sp}^{3}$ hybridized $\mathrm{C}-\mathrm{H}$ vibrational modes. Correlations between the formation of aliphatic and olefinic/aromatic moieties with post-reaction characterization leads to the proposal of a number of chemical transformations that, collectively, define the conditioning phase of the catalyst under the specified set of reaction conditions. A comparison between the inelastic neutron scattering spectra of the $24 \mathrm{~h}$ sample with that of an iron catalyst extracted from a commercial grade Fischer-Tropsch reactor validates the relevance of the experimental approach adopted.
\end{abstract}

\section{Introduction}

Fischer-Tropsch synthesis (FTS) is a non-selective heterogeneously catalyzed industrial reaction that can produce a variety of hydrocarbon products from the reaction of $\mathrm{CO}$ and $\mathrm{H}_{2}$ (syngas) obtained from coal, natural gas or biomass sources..$^{1-3}$ These hydrocarbon products may be further processed to produce sulfur-free diesel and high value chemicals utilized by the chemical manufacturing industry. ${ }^{4}$ If the syngas mixture is sourced from oil-free resources such as coal, FTS is considered an alternative route towards the production of fuel, thereby alleviating the dependency of crude oil derived hydrocarbons. ${ }^{\mathbf{5}, \mathbf{6}}$ Several variants of the process operate around the world, with catalysts predominantly based on Fe and Co containing materials. ${ }^{3}$ The high hydrogen content of natural gas is suited to Co catalysts, whereas hydrogen deficient syngas from biomass and coal is suited to Fe catalysts due to its high activity for water gas shift (WGS) chemistry. ${ }^{7}$

${ }^{a}$ School of Chemistry, Joseph Black Building, University of Glasgow, Glasgow, G12 8QQ, UK. E-mail: David.Lennon@glasgow.ac.uk; Tel: +44-141-330-4372

${ }^{b}$ School of Chemistry, University of St Andrews, St Andrews, KY16 9ST, UK

${ }^{c}$ Group Technology, Research and Technology, Sasol Ltd, UK

${ }^{d}$ ISIS Facility, STFC Rutherford Appleton Laboratory, Chilton, Didcot, Oxon OX11 $O Q X, U K$

$\dagger$ Electronic supplementary information (ESI) available. See DOI: 10.1039/c8ra09731c
Despite its widespread industrial usage, the mechanism by which Fe-based catalysts operate is still debated in the literature. This is in part due to the complexity of the catalyst composition under reaction conditions where a mixture of iron oxides, iron carbides and carbonaceous material can be identified..$^{2,8-10}$ Further, the reaction conditions necessary to induce FTS activity (high pressure/temperature) and the formation of high molecular weight products means in situ analysis of the active catalyst system is challenging. Xu and Bartholomew used high pressure in situ Mössbauer absorption spectroscopy to study the phase transformation of an Fe-based catalyst under realistic FTS conditions (10 atm, $538 \mathrm{~K}) .{ }^{11}$ Other in situ studies utilizing X-ray absorption spectroscopy (XAS), X-ray diffraction (XRD), and scanning transmission X-ray microscopy (STXM) have also been reported..$^{12-14}$ An alternative approach to in situ analysis is to investigate the Fe catalyst undergoing ambient pressure hydrogenation of $\mathrm{CO}$ at elevated temperatures. ${ }^{\mathbf{1 5}}$ Although no polymerization occurs to form the typical distribution of high molecular weight hydrocarbon products, the surface chemistry involved in $\mathrm{CO} / \mathrm{H}_{2}$ dissociation and $\mathrm{C}-\mathrm{C} / \mathrm{C}-\mathrm{H}$ bond formation is informative and relevant.

Previous studies from this group have utilized this test reaction to study how hydrogen is partitioned within the catalyst matrix of reacted Fe FTS catalysts through the application of inelastic neutron scattering (INS). ${ }^{16-19}$ From measuring industrially reacted and laboratory prepared Fe FTS catalysts, the formation of hydrocarbonaceous deposits during the large scale 
FTS operation and the representative laboratory reaction was established. A further study found that $\mathrm{H}_{2}$ pre-treatment before the CO hydrogenation reaction increased the level of hydrocarbonaceous species present on the sample, particularly $\mathrm{sp}^{2}$ hybridized carbon moieties. ${ }^{18}$ These investigations led to the proposal that the polyaromatic overlayer found on these reacted Fe catalysts could have a role in the mediation and transfer of reactive species to catalytic active sites.

For the present study, the temporal dependence of the hydrocarbonaceous overlayer formed on a Fe FTS catalyst during ambient pressure $\mathrm{CO}$ hydrogenation $\left(\mathrm{H}_{2}: \mathrm{CO}=2: 1\right.$, $623 \mathrm{~K}$ ) is analyzed post-reaction using a combination of characterization techniques: temperature-programmed oxidation (TPO), powder X-ray diffraction (XRD), Raman spectroscopy, transmission electron microscopy (TEM) and INS. For the first time, the INS spectra reveal a progressive retention of hydrogenous species as a function of time-on-stream that is associated with the evolution of the hydrocarbonaceous overlayer. Correlations between the formation of aliphatic and olfenic/aromatic moieties with post-reaction TPO profiles, plus other analytical probes, leads to the proposal of a number of chemical transformations that collectively define the conditioning phase of the catalyst under the specified set of reaction conditions. A comparison between the INS spectra of a $24 \mathrm{~h}$ reacted sample with an Fe FTS catalyst extracted from a commercial grade FTS reactor indicates the relevance of the experimental approach adopted. A qualitative model is proposed to account for the experimental observations.

\section{Experimental}

\subsection{Catalyst preparation and characterization}

The iron oxide catalyst sample used for this investigation was prepared using the co-precipitation of iron nitrate (Sigma Aldrich, 99.99\%) and sodium carbonate (Sigma Aldrich, 99.99\%). The preparative procedure utilizes a batch reactor apparatus for reproducible sample synthesis and is described elsewhere. ${ }^{19}$ The procedure produces hematite $\left(\alpha-\mathrm{Fe}_{2} \mathrm{O}_{3}\right)$ with a surface area of $70.8 \mathrm{~m}^{2} \mathrm{~g}^{-1}$ and an absence of promoters/ modifiers. All samples were ground and sieved to a particle size range of $250-500 \mu \mathrm{m}$.

\subsection{Micro-reactor measurements}

Initial reaction testing was performed using a catalyst test line composed of $1 / 8$ in. diameter stainless steel Swagelok tubing; a description of which can be found elsewhere. ${ }^{20,21}$ Approximately $40 \mathrm{mg}$ of catalyst was loaded into a $1 / 4 \mathrm{in}$. quartz tube reactor with the reactor plugged with quartz wool. The reactor is housed within a tube furnace (Carbolite MTF 10/15/30) equipped with PID control. A thermocouple is positioned within the catalyst bed to ensure accurate temperature reading during measurements. For CO hydrogenation reactions ambient pressure gas flows of CO (3.35 sccm, CK Gas, 99.8\%), $\mathrm{H}_{2}$ (6.75 sccm, BOC Ltd, 99.8\%) and He (21.25 sccm, BOC Ltd, 99.9\%) were established over the bypass before introduction to the catalyst reactor (total weight hourly space velocity (WHSV) of $60.8 \mathrm{~h}^{-1}$ ).
All gas flows were monitored using an in-line quadrupole mass spectrometer (Hiden Analytical, HPR-20) attached to the reactor exit line via a differentially-pumped, heated quartz capillary. Under a continuous feed of reactant gases, the sample was subjected to a temperature ramp of $5 \mathrm{~K} \mathrm{~min}^{-1}$ to $623 \mathrm{~K}$ and held for a pre-determined length of time $(x)$, after which the reactant flows were stopped and the sample was cooled to room temperature under the helium carrier gas. The micro-reactor samples are referred to as MR- $x$, where $x$ indicates the time on stream in hours. For ex situ characterization, reacted samples were subjected to a passivation procedure involving the introduction of small amounts of $\mathrm{O}_{2}$ to the reactor, gradually increasing to atmospheric levels (i.e. $20 \% \mathrm{O}_{2}$ in the gas feed). ${ }^{22}$ As mentioned elsewhere, ${ }^{17}$ electing to operate syngas reactions at ambient pressure permits access to $\mathrm{Fe} / \mathrm{CO} / \mathrm{H}_{2}$ surface chemistry whilst ensuring the $\mathrm{C}-\mathrm{C}$ propagation stage is inaccessible, as the latter would otherwise lead to products that would dominate the INS spectrum. Thus, the approach adopted here enables the investigation of surface species to take place without such species being 'swamped' by a high molecular weight product slate.

\subsection{Inelastic neutron scattering measurements}

For INS measurements, approximately $10 \mathrm{~g}$ of catalyst was loaded into an Inconel reactor cell and attached to a custom built sample preparation rig. ${ }^{23}$ For ambient pressure CO hydrogenation measurements, the iron oxide catalyst was heated to $623 \mathrm{~K}$ at $5 \mathrm{~K} \mathrm{~min}^{-1}$ under a flow of CO $75 \mathrm{sccm}$, CK gas, $99.9 \%$ ) and $\mathrm{H}_{2}$ (150 sccm, CK gas, 99.9\%) in a carrier gas (He, $600 \mathrm{sccm}$, CK gas, 99.9\%, total WHSV of $1.47 \mathrm{~h}^{-1}$ ) and held at temperature for a pre-determined length of time. The gas products were analyzed by an in-line mass spectrometer (Hiden Analytical, HPR20 QMS Sampling System). Note that the MS instrument utilized for these scaled-up reaction measurements at the Central Facility is uncalibrated at the time of measurement, therefore the gas traces are a qualitative representation of the reaction profiles. Once the specific reaction had finished, the reactant gases were stopped and the sample allowed to cool to room temperature under the carrier gas. The samples prepared in the large scale reactor are referred to as LR- $x$, where $x$ indicates the time on stream in hours. The reactor cell was isolated and placed in the argon-filled glove box (MBraun UniLab MB-20-G, $\left[\mathrm{H}_{2} \mathrm{O}\right]<1 \mathrm{ppm},\left[\mathrm{O}_{2}\right]<2 \mathrm{ppm}$ ) before being loaded into an aluminum sample holder that is then sealed via an indium wire gasket. ${ }^{24}$ All INS measurements were performed using the MAPS direct geometry spectrometer. ${ }^{25}$ Spectra were recorded at $20 \mathrm{~K}$ at an incident neutron energy of $600 \mathrm{meV}$ and $250 \mathrm{meV}$ using the A-chopper package. Quantification of the $\nu(\mathrm{C}-\mathrm{H})$ feature obtained by INS was achieved following a calibration protocol described elsewhere. ${ }^{26}$ Briefly, samples containing known masses of a polystyrene calibrant (Sigma Aldrich, $>99.0 \%$, typical molecular weight $=350000$ ) were analyzed using the MAPS spectrometer at an incident energy of $600 \mathrm{meV}$. The resulting spectra were baseline corrected and fitted with Gaussian functions using the Origin graphical software package (MicroCal Origin, Version 8.0, Fig. S1†). The integrated 
response was related to hydrogen content of the calibrant material; the calibration plots are presented in the ESI (Fig. S1†).

\subsection{Post-reaction analysis}

TPO of the micro-reactor samples was performed post-reaction in situ whilst the large scale reactor was performed ex situ. Oxygen ( $5 \%$ in $\mathrm{He}, 70 \mathrm{sccm}$, BOC Ltd, 99.5\%) was introduced to the sample (ca. $40 \mathrm{mg}$ ) and the reactor heated to $1173 \mathrm{~K}$ at $5 \mathrm{~K} \mathrm{~min}^{-1}$ using the mass spectrometer to monitor the eluting gases. Quantification of the $\mathrm{CO}_{2}$ peak area was achieved by measuring the $\mathrm{CO}_{2}$ response from the in situ TPO of known masses of graphite (Sigma Aldrich, 99.9\%). ${ }^{27}$ Powder XRD was performed using a Siemens D5000 diffractometer, with a $\mathrm{Cu} \mathrm{K} \alpha$ radiation in Bragg-Brentano geometry in the $2 \theta$ range $5-85^{\circ}$ (step size $0.02^{\circ}$ $\mathrm{s}^{-1}$ ). For in situ XRD studies ca. $200 \mathrm{mg}$ of ground sample was placed in an Anton Paar XRK-900 reaction chamber with a K-type thermocouple was housed in the reaction chamber. Temperature control was maintained by an Anton Paar TCU 750 temperature control unit equipped with a PID control (Eurotherm 2604). A $\mathrm{H}_{2}$ : CO mixture $(2: 1,10 \mathrm{sccm}$, CK Gases, 99.5\%) in carrier gas (Ar, $20 \mathrm{sccm}$, BOC Ltd, 99.9\%) were introduced via 1/4 in. Swagelok tube gas lines, with a thermocouple positioned within the catalyst bed to ensure accurate temperature reading during measurements. The sample was heated to $623 \mathrm{~K}$ at $5 \mathrm{~K} \mathrm{~min}^{-1}$ and maintained at $623 \mathrm{~K}$ for $24 \mathrm{~h}$. Diffractograms were recorded every hour. Reflections were assigned based on the following reference diffraction patterns; $\alpha-\mathrm{Fe}_{2} \mathrm{O}_{3}$, JCPDS \#13-534; $\mathrm{Fe}_{3} \mathrm{O}_{4}$, JCPDS \#19629; $\mathrm{Fe}_{5} \mathrm{C}_{2}$, JCPDS \#36-1248; $\mathrm{Fe}_{3} \mathrm{C}$, JCPDS \#32-0772. Ex situ Raman scattering was performed using a Horiba Jobin Yvon LabRam HR confocal Raman microscope and a $532 \mathrm{~nm}$ laser source at $<20 \mathrm{~mW}$ power. Measurements were taken for approximately $5 \mathrm{~min}$. TEM was performed using a Tecnai T20 microscope equipped with a post-column Gatan Imaging Filter and operated with an accelerating voltage of $200 \mathrm{keV}$. Elemental maps were produced using energy filtered TEM (EFTEM), adopting the three window technique to distinguish the O-K, C-K and Fe-L2.3 EELS edges from a power law background. Samples were ground and suspended in $\mathrm{MeOH}$ (Sigma Aldrich, 99.8\%) before deposition on a holey carbon grid and dried for insertion in to the microscope chamber.

\section{Results and discussion}

\subsection{Micro-reactor characterization}

Previous characterization efforts have established the phase of the iron oxide catalyst sample, investigated for this study, to be $\alpha-\mathrm{Fe}_{2} \mathrm{O}_{3} \cdot{ }^{19}$ Those studies also discussed the reaction chemistry during the representative FTS reaction (ambient pressure CO hydrogenation at $623 \mathrm{~K}$ for $6 \mathrm{~h}$ ). ${ }^{19}$ The focus for this particular investigation is on the temporal behavior of the hydrocarbon retention process during $\mathrm{CO}$ hydrogenation. The reaction was repeated for several samples whilst varying the time-on-stream $(0,3,6,12$, and $24 \mathrm{~h})$. Fig. $\mathrm{S} 2 \dagger$ presents the reaction profile obtained after $24 \mathrm{~h}$. As for the previously reported $6 \mathrm{~h}$ reaction, ${ }^{19}$ three stages are identified: the reduction of the $\alpha-\mathrm{Fe}_{2} \mathrm{O}_{3}$ to $\mathrm{Fe}_{3} \mathrm{O}_{4}$ by $\mathrm{CO}$ to produce $\mathrm{CO}_{2}$ (Stage I), the simultaneous production of $\mathrm{CO}_{2}, \mathrm{H}_{2} \mathrm{O}$, and $\mathrm{CH}_{4}$ with a corresponding consumption of $\mathrm{CO}$ and $\mathrm{H}_{2}$ at $623 \mathrm{~K}$ (Stage $\mathrm{II}$ ), and a decrease in product yield towards steady-state operation (Stage III). A degree of WGS activity could additionally be contributing to the observed reaction profile. $\mathrm{CO}$ conversion approximates to $<1 \%$ and is minimal during the course of the reaction measurement, corresponding to an iron time yield of $1.6 \times 10^{-5} \mathrm{~mol} \mathrm{CO} \mathrm{g}_{\mathrm{Fe}}{ }^{-1} \mathrm{~s}^{-1}$ (Fig. 1a). This is a comparable rate to values reported for similar reaction conditions. ${ }^{28}$ The catalyst retains this low activity throughout the course of the $24 \mathrm{~h}$ reaction without deactivation. In situ XRD identifies the morphological transformations during this period, with the reduction of $\alpha-\mathrm{Fe}_{2} \mathrm{O}_{3}$ to $\mathrm{Fe}_{3} \mathrm{O}_{4}$ leading to the formation of iron carbides (Fig. 1b). It is noted that the gas exchange characteristics of the in situ XRD cell are different to the micro-reactor set-up (not least, a larger sample mass in the in situ XRD reaction cell). This is thought to lead to a prolongation of the reduction period, i.e. Stage I (Fig. S2 $\dagger$ ), with the consequence that the presence of iron oxide phases persists for longer in the XRD cell than occurs in the microreactor. From $6.6 \mathrm{~h}$ onwards (not shown) there was a substantial decrease in signal-to-noise attributed to carbon build-up.

In situ TPO has been demonstrated to be a useful tool in discriminating and quantifying transient carbon species formed under CO hydrogenation conditions at $623 \mathrm{K.} .^{19}$ From our previous study, three peaks were observed after $6 \mathrm{~h}$ onstream and were assigned to reactive adsorbed carbon $(\alpha)$, amorphous-like carbon $(\beta)$ and iron carbides $(\gamma)$ (Fig. 1c).${ }^{19}$ Here we observe the formation of these peaks occurring between 0 to $3 \mathrm{~h}$ at $623 \mathrm{~K}$ (Fig. 1c), concurrent with the reduction of $\alpha-\mathrm{Fe}_{2} \mathrm{O}_{3}$ to $\mathrm{Fe}_{3} \mathrm{O}_{4}$ and beginning of iron carbide formation. Therefore, we propose the origins of these peaks are related with carbon deposition via a combination of CO dissociation/ disproportionation and carbide formation, indicative of the 'evolutionary' nature of iron oxide FTS catalysis as discussed by Schulz. ${ }^{29}$ Table 1 gathers the quantified peak areas for the $\alpha$, $\beta$ and $\gamma$ peaks. After $6 \mathrm{~h}$ on-stream, the $\alpha$ peak is lost, whilst the $\beta$ and $\gamma$ peaks remain. The $\beta$ peak, attributed to amorphous carbon, continues to increase in mass during the course of the reaction. The $\gamma$ peak, ascribed to iron carbide species, levels after about $12 \mathrm{~h}$ on-stream. The increase in carbon retention is also observable by Raman spectroscopy (Fig. 1d) and, combined with the CO conversion, in situ XRD and TPO data, indicates that the carbon speciation is still in dynamic flux after $24 \mathrm{~h}$ reaction. Visualization of the $24 \mathrm{~h}$ reacted sample by ex situ TEM identifies a core shell structure containing a thick outer layer of approximately $5 \mathrm{~nm}$ (Fig. 2), consistent with other microscopy studies of reacted iron FTS catalysts. ${ }^{17,19,30-32}$ The lattice fringes observable within the central core (site A) were found to be $0.190 \mathrm{~nm}$, consistent with iron carbide (e.g. Hägg carbide, $d(600)=0.191 \mathrm{~nm}),{ }^{18}$ whilst the fringes surrounding the core suggest a graphitic character to the encapsulating carbon. Energy filtered micrographs confirm the presence of iron and carbon throughout the cores, without significant oxygen content. Low levels of oxygen are observed, however, within a minority of small dense regions that also contain iron but are smaller than the dominant nanoparticles (Fig. S3 $\dagger$ ). 
a)

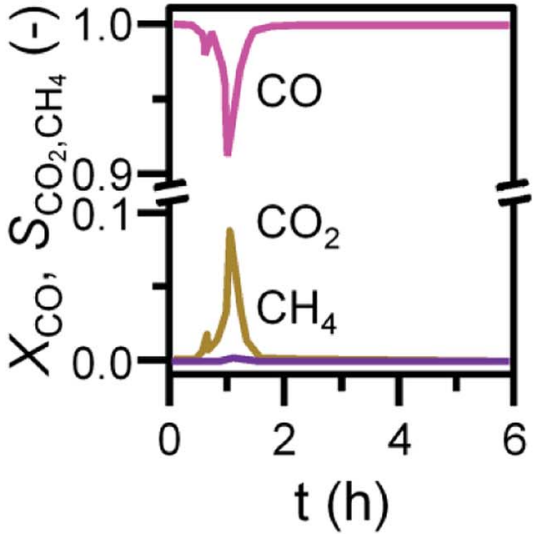

c)
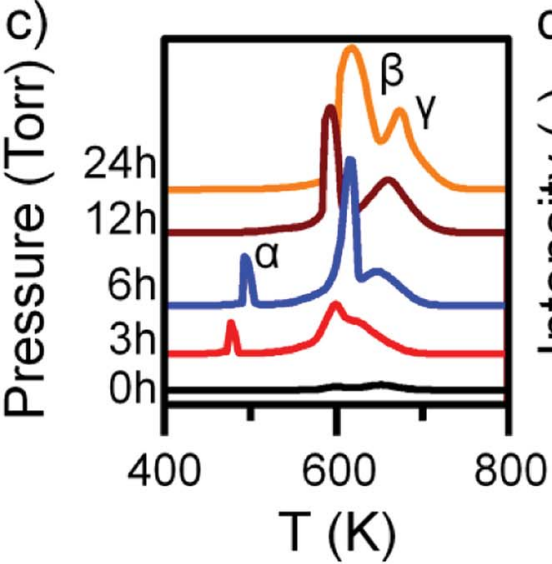

b)

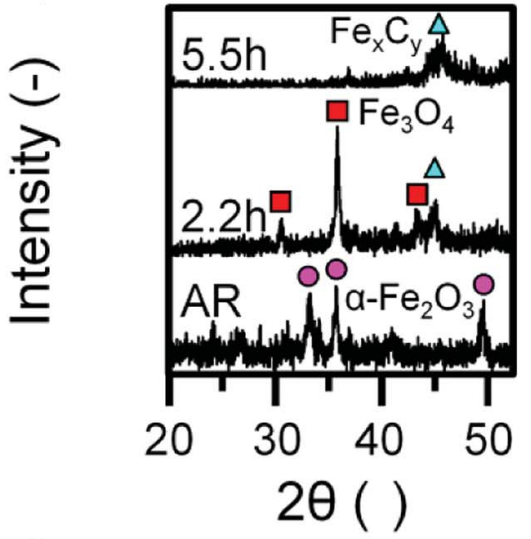

d)

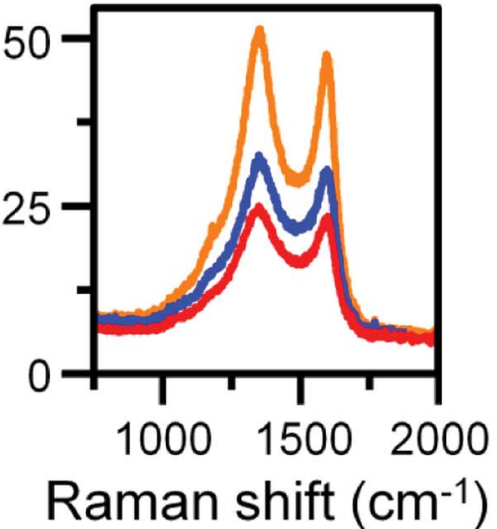

Fig. 1 (a) The conversion of $\mathrm{CO}$ and selectivity to $\mathrm{CO}_{2}$ and $\mathrm{CH}_{4}$ over the $\alpha-\mathrm{Fe}_{2} \mathrm{O}_{3}$ sample during $\mathrm{CO}$ hydrogenation at $623 \mathrm{~K}$ in the micro-reactor. (b) In situ XRD with identified reflections attributed to $\alpha-\mathrm{Fe}_{2} \mathrm{O}_{3}$ (circle), $\mathrm{Fe}_{3} \mathrm{O}_{4}$ (square), and iron carbides (triangle). (c) In situ TPO MS profiles and (d) selected ex situ Raman spectra of the $\alpha-\mathrm{Fe}_{2} \mathrm{O}_{3}$ sample after $\mathrm{CO}$ hydrogenation at $623 \mathrm{~K}$ in the micro-reactor. TPO profiles are stacked to facilitate comparison.

These types of structure were also reported in our previous studies and could either represent unreduced iron oxide or metallic iron which has re-oxidized under the passivation conditions exposed to the catalyst before the ex situ analysis. ${ }^{17,19}$

Table 1 A comparison of the quantified peak area and temperature max from the TPO studies involving samples from the micro-reactor and large scale reactor samples

\begin{tabular}{|c|c|c|c|c|c|c|}
\hline \multirow[b]{2}{*}{ Sample } & \multicolumn{2}{|l|}{$\alpha$ peak } & \multicolumn{2}{|l|}{$\beta$ peak } & \multicolumn{2}{|l|}{$\gamma$ peak } \\
\hline & C content ${ }^{c}$ & $T_{\max }^{d}$ & C content & $T_{\max }$ & C content & $T_{\max }$ \\
\hline${\mathrm{MR}-0^{a}}^{a}$ & - & & 1.04 & 600 & 2.07 & 653 \\
\hline MR-3 & 3.32 & 477 & 13.83 & 600 & 5.89 & 628 \\
\hline MR-6 & 4.14 & 494 & 16.81 & 611 & 8.04 & 649 \\
\hline MR-12 & - & & 18.09 & 592 & 18.51 & 660 \\
\hline MR-24 & - & & 33.43 & 618 & 24.04 & 674 \\
\hline $\mathrm{LR}^{-} 3^{b}$ & 2.65 & 465 & 16.80 & 585 & 2.50 & 619 \\
\hline LR-6 & 2.69 & 482 & 18.42 & 595 & 7.30 & 629 \\
\hline LR-12 & 10.13 & 487 & 23.41 & 597 & 5.95 & 630 \\
\hline LR-24 & 15.98 & 500 & 26.58 & 606 & 11.66 & 639 \\
\hline
\end{tabular}

${ }^{a}$ MR - micro-reactor. ${ }^{b}$ LR - large scale reactor. ${ }^{c}$ Carbon content in mmoles $_{\mathrm{C}}{ }^{d} T_{\max }$ in K.

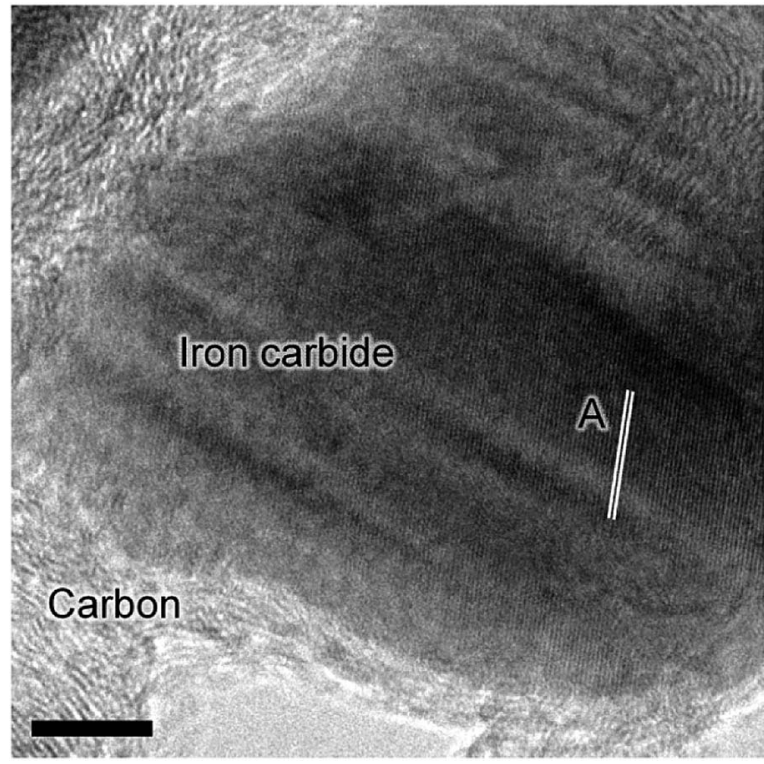

Fig. 2 Ex situ HRTEM micrograph of the post-reaction (24 h) $\alpha-\mathrm{Fe}_{2} \mathrm{O}_{3}$ sample. 


\subsection{Large scale reactor characterization}

Before INS analysis, the $\alpha-\mathrm{Fe}_{2} \mathrm{O}_{3}$ sample was exposed to scaledup CO hydrogenation conditions using a custom built apparatus for the preparation of large catalyst samples (ca. $10 \mathrm{~g}$ ) suitable for INS analysis. ${ }^{23}$ The MS reaction profile for the $24 \mathrm{~h}$ reacted sample is presented in Fig. S4. $\dagger$ As with the microreacted sample (Fig. $\mathrm{S} 2 \dagger$ ), the large scale reaction profile can be defined by several stages: the simultaneous production of $\mathrm{CO}_{2}, \mathrm{H}_{2} \mathrm{O}$ and $\mathrm{CH}_{4}$ once at the reaction temperature, followed by pseudo-steady state operation after approximately $12 \mathrm{~h}$ onstream. It should be noted no wax products were formed during the course of this measurement, confirming that the selected operational regime does not induce the formation of long chain hydrocarbons usually associated with the FTS process that is favored at elevated pressures. The primary route of formation of $\mathrm{CO}_{2}$ in the micro-reactor set-up was the reduction of $\alpha-\mathrm{Fe}_{2} \mathrm{O}_{3}$ to $\mathrm{Fe}_{3} \mathrm{O}_{4}$ by CO. From the selectivity: conversion profile in Fig. 3 a the sharp decrease in $\mathrm{CO}_{2}$ signal coincides with the CO signal approaching steady-state. This would indicate the $\alpha-\mathrm{Fe}_{2} \mathrm{O}_{3}$ has been reduced to $\mathrm{Fe}_{3} \mathrm{O}_{4}$, decreasing the routes of $\mathrm{CO}_{2}$ production. Reflecting the larger sample mass utilized for the large scale reaction ( $10 \mathrm{~g}$ versus $40 \mathrm{mg}$ in the micro-reactor), longer run times are required to fully reduce the $\alpha-\mathrm{Fe}_{2} \mathrm{O}_{3}$ starting material when compared with the micro-reactor arrangement. Ex situ XRD indicates the complete reduction of $\alpha-\mathrm{Fe}_{2} \mathrm{O}_{3}$ from $12 \mathrm{~h}$ (Fig. 3b). Further, there is an increase in iron carbide reflections between 40 and $50^{\circ}$ up to $24 \mathrm{~h}$. The increase is less than observed for the in situ measurement where, after approximately $5 \mathrm{~h}$ on-stream, the diffractogram was dominated by iron carbide features (Fig. 1b). This observation is consistent with the inferior solid/gas exchange dynamics of the INS reactor.

In contrast to the micro-reactor TPO profiles (Fig. 1c), the TPO profiles obtained for the large scale reactor samples are similar in profile shape; the $\alpha$ peak is sharp and defined, whilst the $\beta$ peak is broad, containing a high temperature shoulder $(\gamma$ peak, Fig. 3c). The quantified peak areas are collected in Table 1. As with the micro-reactor studies, carbon retention increases during the course of the reaction, particularly the reactive adsorbed carbon associated with the $\alpha$ peak.

This species is only present for the first $6 \mathrm{~h}$ of reaction in the micro-reactor (Fig. 1c), suggesting the large scale operation enables this carbon species to persist for longer periods of timeon-stream consistent with the inferior gas/solid exchange a)
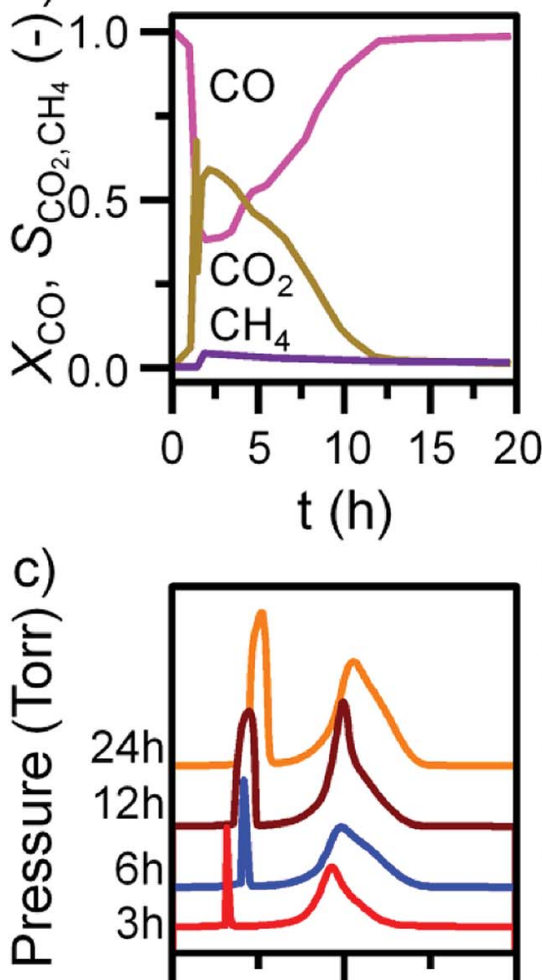

b)

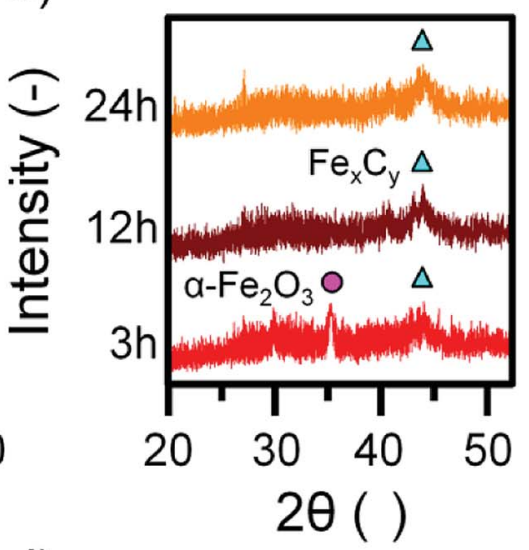

d)

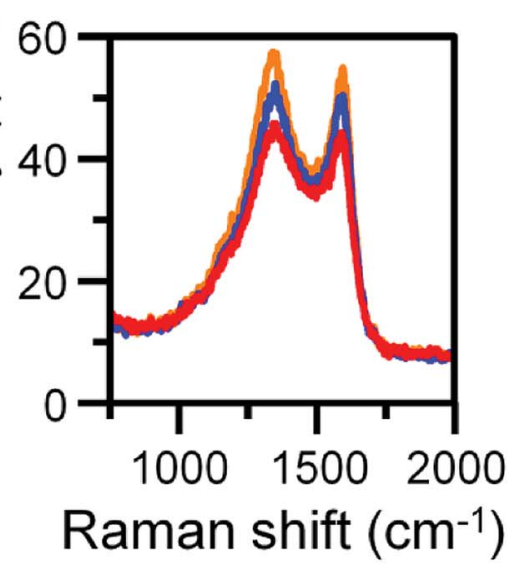

Fig. 3 (a) The conversion of $\mathrm{CO}$ and selectivity to $\mathrm{CO}_{2}$ and $\mathrm{CH}_{4}$ over the $\alpha-\mathrm{Fe}_{2} \mathrm{O}_{3}$ sample during $\mathrm{CO}$ hydrogenation at $623 \mathrm{~K}$ in the large scale reactor. (b) Ex situ XRD with identified reflections attributed to $\alpha$-Fe $\mathrm{O}_{3}$ (circle), and iron carbides (triangle). (c) Ex situ TPO MS profiles and (d) selected ex situ Raman spectra of the $\alpha-\mathrm{Fe}_{2} \mathrm{O}_{3}$ sample after $\mathrm{CO}$ hydrogenation at $623 \mathrm{~K}$ in the large scale reactor. TPO profiles are stacked to facilitate comparison. 
dynamics. Ex situ Raman spectra are defined by the 'D' and 'G' bands indicative of disordered and ordered carbonaceous deposits (Fig. 3d). ${ }^{33-35}$ The small increase in intensity from 3 to $24 \mathrm{~h}$ is consistent with the increase in carbon retention observed by TPO (Fig. 3c, Table 1).

\subsection{Inelastic neutron scattering studies}

Fig. 4 and 5 presents the INS spectra of the reacted samples recorded at an incident energy of 600 and $250 \mathrm{meV}$ respectively. At $600 \mathrm{meV}$, the spectra are defined by the presence of a $\nu(\mathrm{C}-\mathrm{H})$
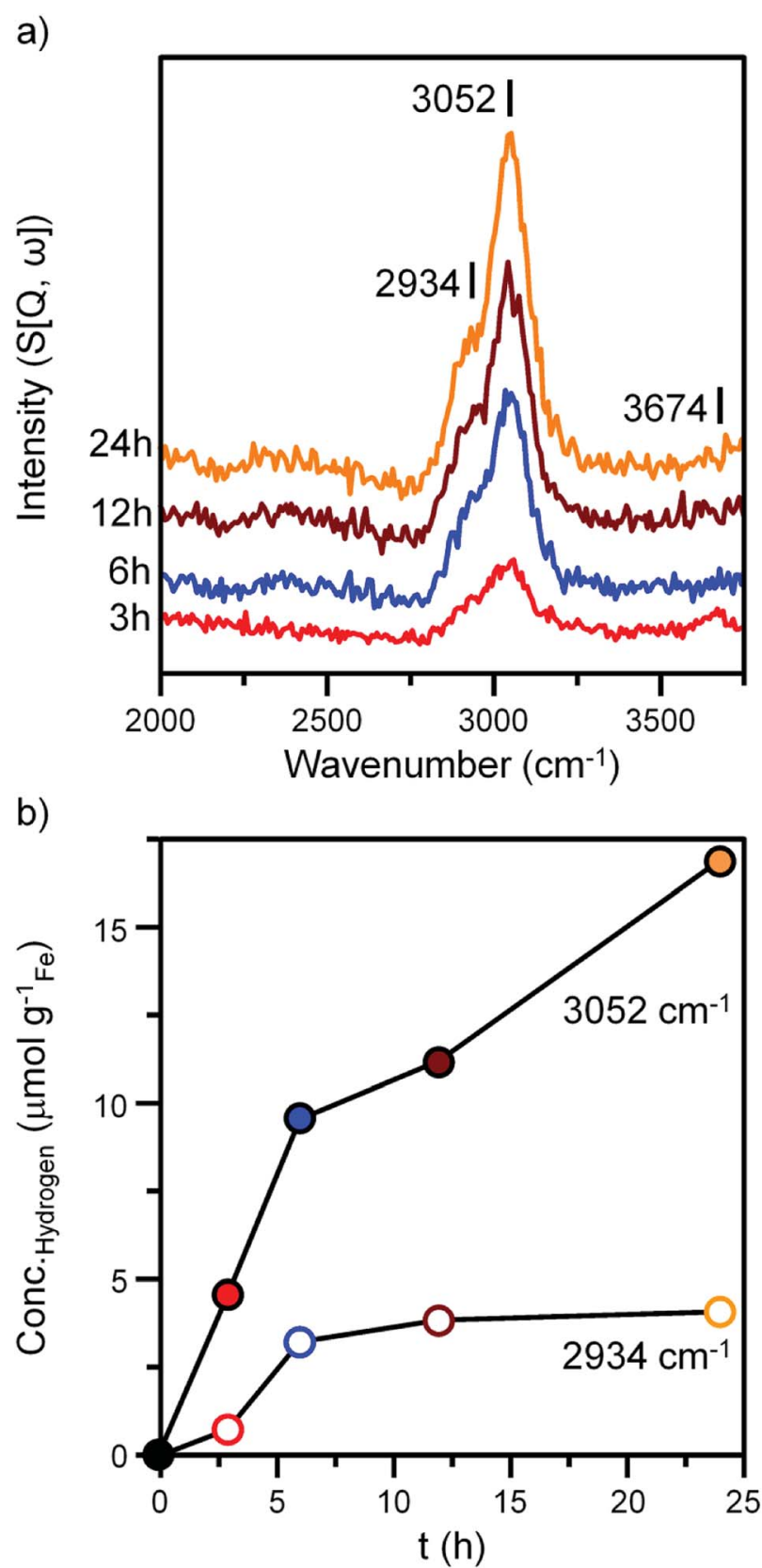

Fig. 4 (a) INS spectra (recorded at $600 \mathrm{meV}$ ) of the $\alpha-\mathrm{Fe}_{2} \mathrm{O}_{3}$ after $\mathrm{CO}$ hydrogenation at $623 \mathrm{~K}$ in the large scale reactor. Spectra are stacked to facilitate comparison. (b) The quantified hydrogen content of the $2934 \mathrm{~cm}^{-1}$ (hollow) and $3052 \mathrm{~cm}^{-1}$ (solid) features identified in part (a). feature consisting of a main peak at $3052 \mathrm{~cm}^{-1}$ with a noticeable shoulder at ca. $2934 \mathrm{~cm}^{-1}$ (Fig. 4a). These bands are assigned to the $\nu(\mathrm{C}-\mathrm{H})$ modes of $\mathrm{sp}^{2}$ and $\mathrm{sp}^{3}$ hybridized carbon. ${ }^{18,19}$ There is a small but noticeable peak at $3674 \mathrm{~cm}^{-1}$ for the $3 \mathrm{~h}$ reacted sample attributed to the $\nu(\mathrm{O}-\mathrm{H})$ mode of terminal hydroxyl groups. With time-on-stream the intensity of the $\nu(\mathrm{C}-\mathrm{H})$ features increase, whilst the $\nu(\mathrm{O}-\mathrm{H})$ mode is not present from $6 \mathrm{~h}$ onwards indicating a progressive deposition of hydrocarbonaceous material and the removal of the small population of surface hydroxyls.

An advantage of INS is the spectral intensity for a specific mode is directly proportional to the hydrogen concentration. ${ }^{36}$ Integration and quantification of the $\nu(\mathrm{C}-\mathrm{H})$ features via described calibration procedures then enables mode specific hydrogen retention as a function of time-on-stream to be established (Fig. S4b and $55 \dagger$ ). ${ }^{26}$ The aliphatic $\mathrm{sp}^{3}$ hybridized $\mathrm{C}-\mathrm{H}$ mode increases during the initial stages of reaction before saturating after ca. $8 \mathrm{~h}$. In contrast, olefinic/aromatic $\mathrm{sp}^{2}$ hybridized $\mathrm{C}-\mathrm{H}$ species continually increase during the reaction. Correlating the quantified INS trends with the TPO peak profiles (Fig. 3c, Table 1) suggest the $\mathrm{sp}^{2}$ hybridized $\mathrm{C}-\mathrm{H}$ entities are related to the steadily increasing $\beta$ peak, i.e. amorphous carbon. However, the $\mathrm{sp}^{3}$ hybridized $\nu(\mathrm{C}-\mathrm{H})$ signal does not correlate with any of the $\alpha, \beta$ or $\gamma$ peaks present in Fig. 3c. It is possible that desorption or partial oxidation events could be affecting the TPO profiles.

Spectra recorded at an incident energy of $250 \mathrm{meV}$ are presented in Fig. 5. Several weak features are present after $3 \mathrm{~h}$ onstream $\left(1451,1389\right.$ and $1160 \mathrm{~cm}^{-1}$ ) that are assigned to aromatic $\delta(\mathrm{C}-\mathrm{H})$ modes. ${ }^{16-19}$ The $1451 \mathrm{~cm}^{-1}$ feature is assigned to semi-circle ring deformation modes that are possibly linked with a $\delta(\mathrm{C}-\mathrm{H})$ mode associated with perimeter carbons of an

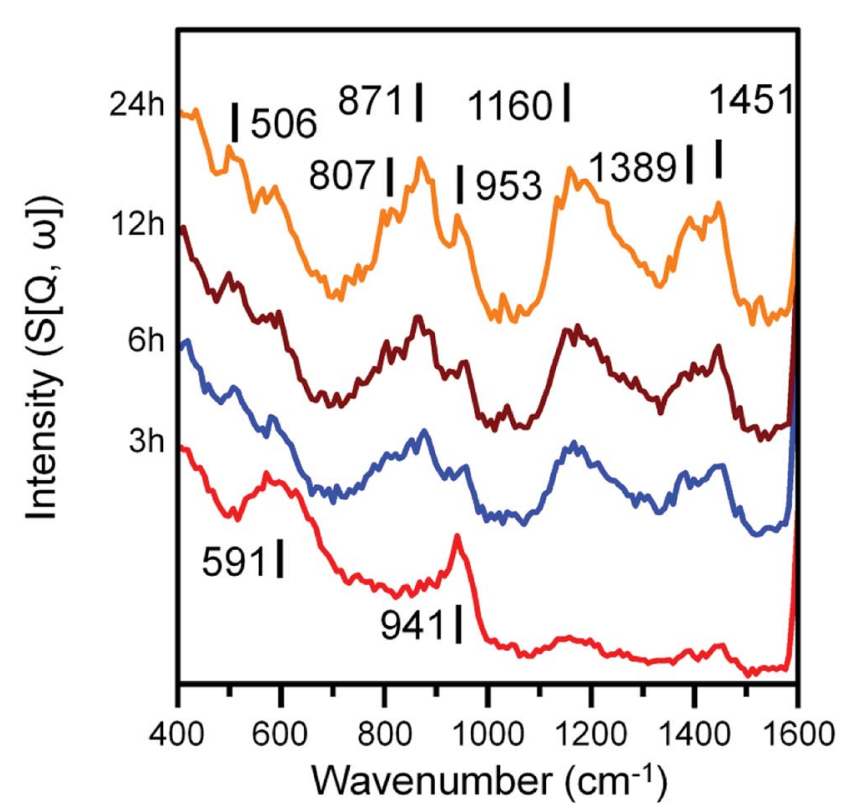

Fig. 5 INS spectra (recorded at $250 \mathrm{meV}$ ) of the $\alpha$ - $\mathrm{Fe}_{2} \mathrm{O}_{3}$ sample after $\mathrm{CO}$ hydrogenation at $623 \mathrm{~K}$ in the large scale reactor. Spectra are stacked to facilitate comparison. 
extended polycyclic aromatic network..$^{37}$ The $1389 \mathrm{~cm}^{-1}$ band is assigned to an in-plane ring deformation of a naphthalene-type molecule and the $1160 \mathrm{~cm}^{-1}$ band is assigned to a $\mathrm{CC}-\mathrm{H}$ inplane deformation mode of a polyaromatic hydrocarbon. The relatively weak intensity of these features suggests the presence of aromatic species at this stage of the reaction is relatively low. The remainder of peaks at $3 \mathrm{~h}$ can be assigned to the $\mathrm{A}_{1 \mathrm{~g}} \mathrm{Fe}-\mathrm{O}$ phonon mode of $\mathrm{Fe}_{3} \mathrm{O}_{4}\left(591 \mathrm{~cm}^{-1}\right)$ and a combination of alkenic $\delta(\mathrm{C}-\mathrm{H})$ and a possible magnetic interaction associated with $\mathrm{Fe}_{3} \mathrm{O}_{4}\left(941 \mathrm{~cm}^{-1}\right) .{ }^{19,38}$ With time-on-stream, the intensity of the $\mathrm{sp}^{2}$ hybridized carbon features between 1000 to $1500 \mathrm{~cm}^{-1}$ increase. The signals observed at 871 and $801 \mathrm{~cm}^{-1}$ for the 6,12 and $24 \mathrm{~h}$ reacted sample spectra can be assigned to the out-ofplane $\mathrm{C}-\mathrm{H}$ deformations of either an olefinic or aromatic group. ${ }^{39}$ The band at $506 \mathrm{~cm}^{-1}$ is assigned to a $\mathrm{C}-\mathrm{C}$ torsion mode of edge carbon atoms contained within a polycyclic aromatic network. ${ }^{37}$

\subsection{Proposed scheme}

Previous studies from this group have investigated an industrially reacted iron based FTS catalyst by INS using the TOSCA instrument. ${ }^{16}$ The spectrum is indicative of hydrocarbonaceous deposits consisting of a polyaromatic overlayer that retains some aliphatic character. ${ }^{16}$ As the MAPS spectrometer is characteristically different from the TOSCA spectrometer (direct versus indirect geometry instruments), ${ }^{25}$ the $24 \mathrm{~h}$ reacted sample was also analyzed using the TOSCA spectrometer for direct comparison with the industrially reacted iron sample (Fig. 6). The spectra exhibit comparable characteristics, particularly in the deformation region between 800 to $1500 \mathrm{~cm}^{-1}$. These similarities indicate hydrocarbonaceous components present

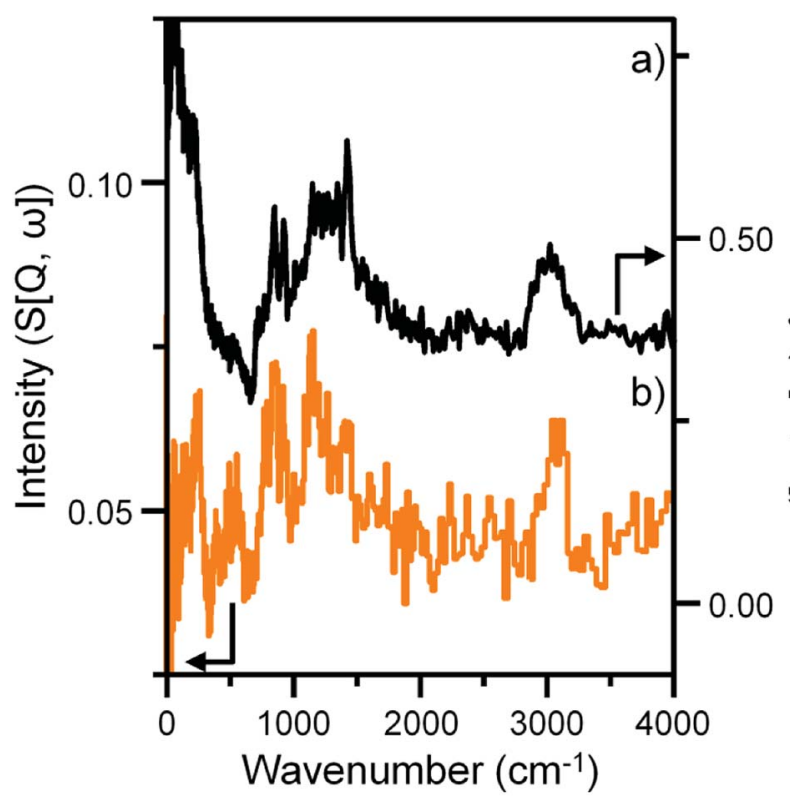

Fig. 6 INS spectral comparison of (a) a reacted commercial grade Fe FTS catalyst after solvent extraction ${ }^{16}$ and (b) the $\alpha-\mathrm{Fe}_{2} \mathrm{O}_{3}$ sample after $\mathrm{CO}$ hydrogenation at $623 \mathrm{~K}$ for $24 \mathrm{~h}$ using the large scale reactor setup. Both spectra were obtained with the TOSCA spectrometer. on each set of samples are composed of similar material, namely a polyaromatic over-layer possessing some aliphatic functionality. Moreover, Fig. 7 shows how the density of the catalyst extracted from the large scale INS reactor is modified as a function of time-on-stream. Catalyst density is seen to decrease sharply over the period $0-6 \mathrm{~h}$ before levelling off at longer reaction times. van der Loosdrecht and co-workers report iron based FTS catalysts to exhibit a decrease in density during reaction; a matter that causes problems in the process environment. ${ }^{3}$ To a first approximation, the trend evident in Fig. 7 is a further indication on the relevance of the selected test regime connects with changes in catalyst structure and composition as encountered in the industrial scenario.

Niemantsverdriet's respected competition model states considers the rates of FTS activity with respect to that of carbide formation. ${ }^{\mathbf{8} 40}$ Here, we adopt those concepts but shift the emphasis to the not unimportant matter of hydrogen supply. Eqn (1) describes the reaction between chemisorbed carbon and hydrogen atoms to form $\mathrm{C}-\mathrm{H}$ products. Under the reaction conditions utilized for this study, it is suggested that the formation of amorphous carbon (eqn (2)) is a result of a hydrogen deficiency within the reaction system, where adsorbed carbon is produced via the dissociative adsorption of CO. It is assumed that the carbon resides at an iron carbide site that supports dissociative adsorption of $\mathrm{CO}^{\mathbf{1 0}}$ Adsorbed hydrogen atoms diffuse to this site and form $\mathrm{C}-\mathrm{H}$ bonds. Whilst a rich hydrogen supply will convey saturated $\mathrm{C}-\mathrm{H}$ bonds, a constrained hydrogen supply will lead to unsaturated $\mathrm{C}-\mathrm{H}$ bonds. Similarly, the formation of amorphous/graphitic carbon $\left(\mathrm{C}_{(\text {poly })}\right)$ or hydrocarbon depends on the hydrogen supply. ${ }^{\mathbf{8 , 4 0}}$

$$
\begin{gathered}
x \mathrm{C}_{(\mathrm{ad})}+y \mathrm{H}_{(\mathrm{ad})} \rightarrow \mathrm{C}_{x} \mathrm{H}_{y} \\
n \mathrm{C}_{(\mathrm{ad})} \rightarrow \mathrm{C}_{(\text {poly }) n}
\end{gathered}
$$

Fig. 8 is schematic representation that elaborates on a previously suggested model. ${ }^{16}$ Roles have now been included

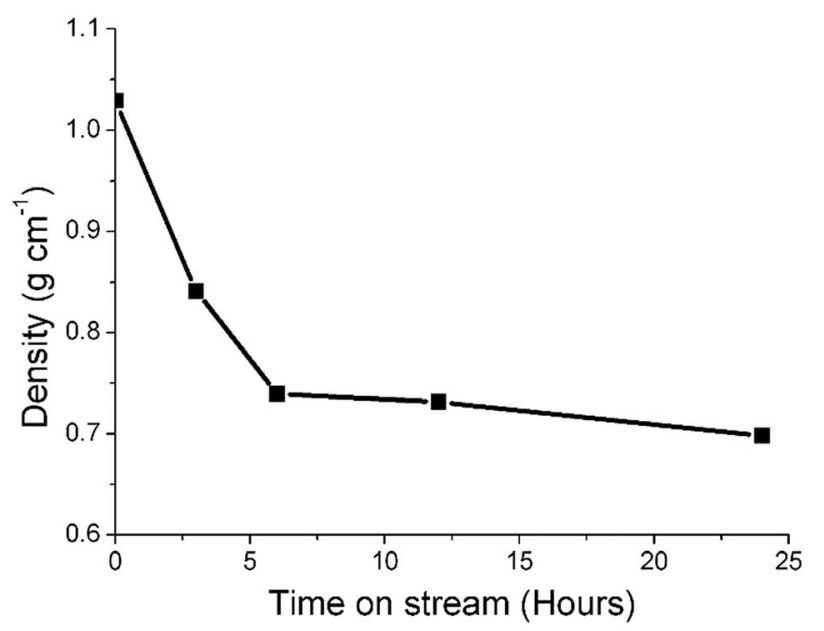

Fig. 7 A plot of density of the catalyst extracted from the large scale INS reactor as a function of time-on-stream (CO hydrogenation at $623 \mathrm{~K})$. 
for (i) a hydrocarbonaceous overlayer and (ii) the effect of hydrogen supply. Sites for the dissociation of $\mathrm{CO}$ and $\mathrm{H}_{2}$ are identified with the hydrocarbonaceous overlayer acting as a mediator for the supply of carbon and hydrogen atoms from these sites. The following statements represent a hypothesis, illustrated in Fig. 8, which seeks to describe how the catalyst conditioning regime results in an active catalytic material capable of sustaining reagent turnover. Firstly, in the reducing environment of a syngas feed at elevated temperatures, the $\alpha$ $\mathrm{Fe}_{2} \mathrm{O}_{3}$ pre-catalyst is reduced to $\mathrm{Fe}_{3} \mathrm{O}_{4}$ which then induces carbide formation. At this stage, as indicated in Fig. 4 and 5, a hydrocarbonaceous overlayer forms. It is assumed that this overlayer forms at the surface of the iron carbide. ${ }^{17}$ Adopting a similar line-of-thought to that considered for certain hydrogenation reactions, ${ }^{41}$ the coverage of the hydrocarbonaceous overlayer is partial, leaving two distinct 'open' sites: A and B. Site $\mathrm{A}$ is associated with the dissociative adsorption of hydrogen that provides a continuous source of hydrogen atoms. Site B is connected with the dissociative adsorption of carbon monoxide to produce chemisorbed carbon and oxygen atoms. Reaction of adsorbed oxygen atoms at this site with either carbon or hydrogen will result in the formation of, respectively, $\mathrm{CO}_{2}$ and $\mathrm{H}_{2} \mathrm{O}$. Alternatively, site B could support reactions described by eqn (1) (site $\mathrm{B}^{1}$ ) and 2 (site $\mathrm{B}^{2}$ ). Under $\mathrm{CO}$ hydrogenation conditions (elevated temperature but low pressure), this will

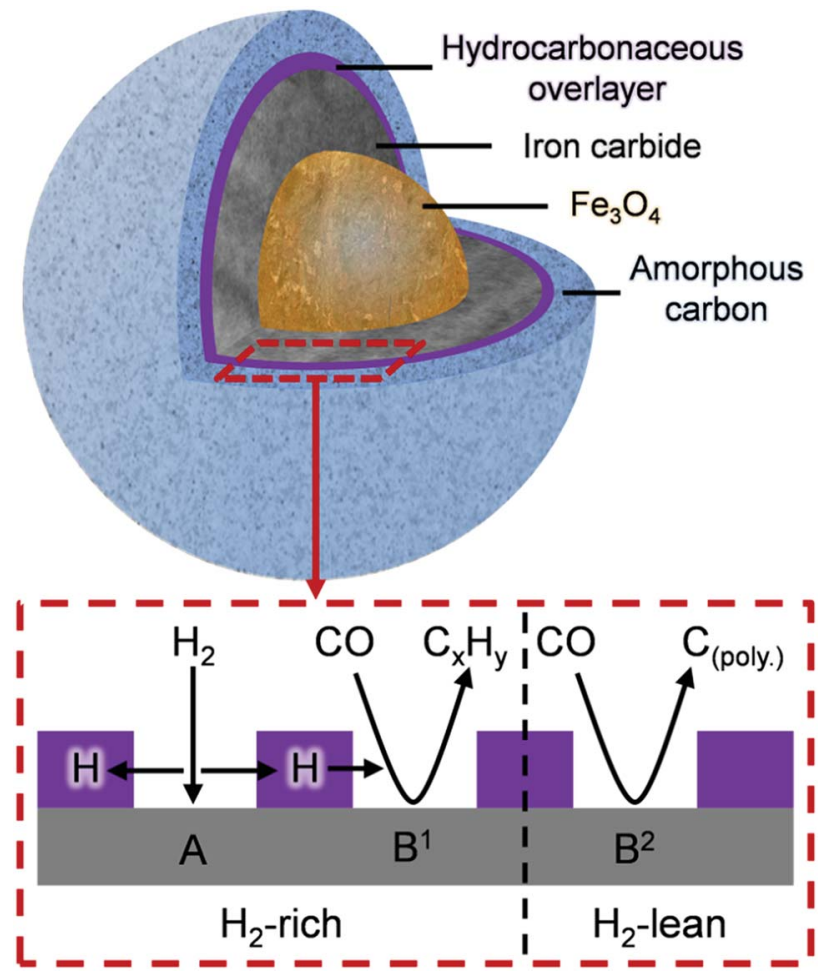

Fig. 8 A schematic indicating the composition of the Fe FTS catalyst after ca. $6 \mathrm{~h}$ ambient pressure $\mathrm{CO}$ hydrogenation at $623 \mathrm{~K}$. The hydrocarbonaceous overlayer (highlighted area) is suggested to mediate the transfer of hydrogen, where under $\mathrm{H}_{2}$-rich conditions, $\mathrm{C}_{x} \mathrm{H}_{y}$ prevails (site $\mathrm{B}^{1}$ ) whilst under $\mathrm{H}_{2}$-lean conditions, carbon polymerization occurs (site $B^{2}$ ). lead to $\mathrm{CH}_{4}$ formation provided the hydrogen supply is sufficient (eqn (1), site $B^{1}$ ). A constrained hydrogen supply will favor the formation of amorphous/graphitic carbon (eqn (2), site $\mathrm{B}^{2}$ ). Under classical FTS conditions (elevated temperature and high pressure), eqn (1) is supplemented by a C-C propagation reaction; a rich and dynamic hydrogen supply to this site will then support formation of high molecular weight saturated products. The hydrocarbonaceous overlayer may therefore represent the precursor to both desired FT product and carbonaceous, or hard, carbon. The fate of the hydrocarbonaceous overlayer will be dependent on hydrogen supply with hard carbon formation occurring under hydrogen lean conditions.

Clearly, further work is required to evaluate the feasibility of the proposed hypothesis but, nevertheless, it can be used to rationalize established trends of Fe based catalysts applied to CO hydrogenation and FTS reactions. The novelty of this particular work is that the INS spectra show, for the first time, that the formation of a hydrocarbonaceous overlayer is an integral part of the catalyst conditioning phase of this intricate catalytic system. Moreover, the INS spectrum of the $24 \mathrm{~h}$ sample is comparable to a commercial grade FTS catalyst extracted from a large-scale coal-to-liquids reactor indicating that a hydrocarbonaceous overlayer is present in both samples (Fig. 6). This outcome validates the use of $\mathrm{CO}$ hydrogenation over a representative iron based FTS catalyst as a test reaction compatible with the acquisition of informative INS spectra.

\section{Conclusions}

CO hydrogenation has been investigated as a function of time over an un-promoted Fe based FTS catalyst and characterized using TPO, XRD, Raman, TEM and INS. The following conclusions can be drawn.

- A temporal profile is constructed from the TPO and INS studies for both the carbonaceous and hydrocarbonaceous components of the reacted catalyst samples.

- TPO profiles are assigned to reactive carbon species, amorphous carbon and iron carbide species; the development of which are dependent on the gas/solid exchange dynamics afforded by either a micro-reactor or a large scale INS reactor.

- INS analysis of the reacted catalyst samples identify the presence of $\mathrm{sp}^{2}$ and $\mathrm{sp}^{3}$ hybridized C-H species, with quantification of the $\nu(\mathrm{C}-\mathrm{H})$ modes indicating the concentration of aliphatic C-H species to saturate after approximately $6 \mathrm{~h}$ timeon-stream. In contrast, the concentration of olefinic/aromatic $\mathrm{C}-\mathrm{H}$ entities progressively increase as a function of time-onstream.

- The INS spectrum for a catalyst that has experienced a $24 \mathrm{~h}$ reaction period yields a comparable INS spectrum to that of a commercial grade Fe based FTS catalyst that has been extracted from a large scale coal-to-liquids unit operation. This establishes the relevance of the hydrocarbonaceous overlayer concept to FTS and, moreover, indicates that the test reaction explores aspects of iron oxide/ $\mathrm{CO} / \mathrm{H}_{2}$ surface chemistry that has tangible connectivity to the economically relevant process chemistry. 
- A schematic illustration (Fig. 8) is presented to define the range of components and probable distribution of sites connected with an active Fe based FTS catalyst.

\section{Conflicts of interest}

There are no conflicts to declare.

\section{Acknowledgements}

Sasol Ltd., the University of Glasgow and the EPSRC (grant numbers EP/P504937/1 and EP/P505534/1) are thanked for the provision of postgraduate studentships (RW and ALD). The STFC Rutherford Appleton Laboratory is thanked for access to neutron beam facilities. Technical assistance in electron microscopy was provided by Dr Donald MacLaren and Mr Colin How (School of Physics and Astronomy, University of Glasgow). The Royal Society is thanked for the provision of an Industrial Fellowship (PBW).

\section{References}

1 A. P. Steynberg, in Studies in Surface Science and Catalysis, ed. A. Steynberg and M. Dry, Elsevier, 2004, ch. 1, vol. 152, pp. 163.

2 E. de Smit and B. M. Weckhuysen, Chem. Soc. Rev., 2008, 37, 2758-2781.

3 J. Van de Loosdrecht, F. G. Botes, I. M. Ciobica, A. Ferreira, P. Gibson, D. J. Moodley, A. M. Saib, J. L. Visage, C. J. Weststrate and J. W. Niemantsverdriet, in FischerTropsch Synthesis: Catalysts and Chemistry. In Comprehensive Inorganic Chemistry II, ed. J. Reedijk and K. Poeppelmeier, Elsevier, Oxford, 2013, ch. 7.20, vol. 7, pp. 525-557.

4 L. P. Dancuart, R. de Haan, and A. de Klerk, in Studies of Surface Science and Catalysis, A. Steynberg and M. Dry, Elsevier, 2004, ch. 6, vol. 152, pp. 472-522.

5 H. Schulz, Appl. Catal., A, 1999, 186, 3-12.

6 Y. Traa, Chem. Commun., 2010, 46, 2175-2187.

7 H. Janhangiri, J. Bennett, P. Mahjoubi, K. Wilson and S. Gu, Catal. Sci. Technol., 2014, 4, 2210-2229.

8 J. W. Niemantsverdriet, A. M. Van der Kraan, W. L. Van Dijk and H. S. J. Van der Baan, J. Phys. Chem., 1980, 84, 33633370 .

9 M. E. Dry, The Fischer-Tropsch Synthesis, Catalysis: Science and Technology, ed. J. R. Anderson and M. Boudart, SpringerVerlag, New York, 1981, pp. 160-255.

10 E. de Smit, F. Cinquini, A. M. Beale, O. V. Safonova, W. van Beek, P. Sautet and B. M. Weckhuysen, J. Am. Chem. Soc., 2010, 132, 14928-14941.

$11 \mathrm{~J} . \mathrm{Xu}$ and C. H. Bartholomew, J. Phys. Chem. B, 2005, 109, 2392-2403.

12 S. Li, S. Krishnamoorthy, A. Li, G. D. Meitzner and E. Iglesia, J. Catal., 2002, 206, 202-217.

13 L. Niu, X. Liu, X. Liu, Z. Lv, C. Zhang, X. Wen, Y. Yang, Y. Li and J. Xu, ChemCatChem, 2017, 9, 1691-1700.
14 E. de Smit, J. F. Creemer, H. W. Zandbergen, B. M. Weckhuysen and F. M. F. de Groot, J. Phys.: Conf. Ser., 2009, 190, 012161.

15 T. Herranz, S. Rojas, F. Perezalonso, M. Ojeda, P. Terreros and J. Fierro, J. Catal., 2006, 243, 199-211.

16 N. G. Hamilton, I. P. Silverwood, R. Warringham, J. Kapitán, L. Hecht, P. B. Webb, R. P. Tooze, S. F. Parker and D. Lennon, Angew. Chem., Int. Ed., 2013, 52, 5608-5611.

17 N. G. Hamilton, R. Warringham, I. P. Silverwood, J. Kapitan, L. Hecht, P. B. Webb, R. P. Tooze, W. Zhou, C. D. Frost, S. F. Parker and D. Lennon, J. Catal., 2014, 312, 221-231.

18 R. Warringham, N. G. Hamilton, I. P. Silverwood, C. How, P. B. Webb, R. P. Tooze, W. Zhou, C. D. Frost, S. F. Parker and D. Lennon, Appl. Catal., A, 2015, 489, 209-217.

19 R. Warringham, A. R. McFarlane, D. A. MacLaren, P. B. Webb, R. P. Tooze, J. Taylor, R. Ewings, S. F. Parker and D. Lennon, J. Chem. Phys., 2015, 143, 174703.

20 A. R. McFarlane, I. P. Silverwood, E. L. Norris, R. M. Ormerod, C. D. Frost, S. F. Parker and D. Lennon, Chem. Phys., 2013, 427, 54-60.

21 A. R. McFarlane, I. P. Silverwood, R. Warringham, E. L. Norris, R. M. Ormerod, C. D. Frost, S. F. Parker and D. Lennon, RSC Adv., 2013, 3, 16577-16589.

22 M. D. Shroff and A. K. Dayte, Catal. Lett., 1996, 37, 101-106. 23 R. Warringham, D. Bellaire, S. F. Parker, J. Taylor, R. A. Ewings, C. M. Goodway, M. Kibble, S. R. Wakefield, M. Jura, M. P. Dudman, R. P. Tooze, P. B. Webb and D. Lennon, J. Phys.: Conf. Ser., 2014, 554, 012005.

24 P. C. H. Mitchell, S. F. Parker, A. J. Ramirez-Cuesta and J. Tomkinson, in Vibrational Spectroscopy Using Neutrons with Applications in Chemistry, Biology, Materials Science and Catalysis. Series on Neutron Techniques and Applications, World Scientific, Singapore, 2005, vol. 3.

25 S. F. Parker, D. Lennon and P. W. Albers, Appl. Spectrosc., 2011, 65, 1325-1341.

26 I. P. Silverwood, N. G. Hamilton, C. J. Laycock, J. Z. Staniforth, R. M. Ormerod, C. D. Frost, S. F. Parker and D. Lennon, Phys. Chem. Chem. Phys., 2010, 12, 31023107.

27 I. P. Silverwood, N. G. Hamilton, A. R. McFarlane, J. Kapitán, L. Hecht, E. L. Norris, R. M. Ormerod, C. D. Frost, S. F. Parker and D. Lennon, Phys. Chem. Chem. Phys., 2012, 14, 1521415225.

28 H. M. T. Galvis, J. H. Bitter, T. Davidian, M. Ruitenbeek, A. I. Dugulan and K. P. de Jong, J. Am. Chem. Soc., 2012, 134, 16207-16215.

29 H. Schulz, Top. Catal., 2003, 26, 73-84.

30 P. C. Thüne, P. Moodley, F. Scheijen, H. Fredricksson, R. Lancee, J. Kropf, J. T. Miller and J. W. Niemantsverdriet, J. Phys. Chem. C, 2012, 116, 7367-7373.

31 M. D. Shroff, D. S. Kalakkad, K. E. Coulter, S. D. Kohler, M. S. Harrington, N. B. Jackson, A. G. Sault and A. K. Datye, J. Catal., 1995, 156, 185-207.

32 P. C. Thüne, C. J. Weststrate, P. Moodley, A. M. Saib, J. van de Loosdrecht, J. T. Miller and J. W. Niemantsverdriet, Catal. Sci. Technol., 2011, 1, 689-697. 
33 A. Sadezky, H. Muckenhuber, H. Grothe, R. Niessner and U. Pöschl, Carbon, 2005, 43, 1731-1742.

34 M. A. Pimenta, G. Dresselhaus, M. S. Dresselhaus, L. G. Cancado, A. Jorio and R. Saito, Phys. Chem. Chem. Phys., 2007, 9, 1276-1291.

35 J. Nemanich and S. A. Solin, Phys. Rev. B, 1979, 20, 392-401. 36 P. W. Albers, D. Lennon and S. F. Parker, Catalysis, in Neutron Scattering: Applications in Biology, Chemistry, and Materials Science, ed. F. Fernandez-Alonzo and D. L. Price, Elsevier, 2017, vol. 49, pp. 279-348.

37 P. W. Albers, J. Pietsch, J. Krauter and S. F. Parker, Phys. Chem. Chem. Phys., 2003, 5, 1941-1949.
38 I. Chamritski and G. J. Burns, J. Phys. Chem. B, 2005, 109, 4965-4968.

39 D. Lin-Vien, N. B. Colthup, W. G. Fateley and J. G. Graselli, The handbook of infrared and Raman characteristic frequencies of organic molecules, Academic Press, Boston, 1991.

40 J. W. Niemantsverdriet and A. M. Van der Kraan, J. Catal., 1981, 72, 385-388.

41 A. Borodzinski and A. Cybulski, Appl. Catal., A, 2000, 198, 5166. 